\title{
Effects of renal transplantation on left ventricular size and function
}

\author{
MARKKU IKÄHEIMO, MARKKU LINNALUOTO, KAISA HUTTUNEN, \\ JUHA TAKKUNEN \\ From the Cardiovascular Division and Dialysis Unit, Department of Medicine, University of Oulu, \\ Finland
}

SUMMARY Thirteen patients with chronic renal failure and uraemia were investigated by echocardiography preoperatively before and after haemodialysis and again after a successful renal transplantation to evaluate the cardiac changes caused by renal transplantation.

After renal transplantation, the left ventricular end-diastolic and end-systolic diameters, as well as the cardiac index, decreased, probably because of the decreased left ventricular filling pressure. The left ventricular wall thickness and mass decreased, apparently as a result of the decrease of the left ventricular preload and also of the decrease of the afterload, because the systolic blood pressure decreased. The left atrial diameter decreased in response to the decreased left ventricular preload and wall hypertrophy.

The changes in the indices of left ventricular function as a result of haemodialysis appeared to predict the changes seen after renal transplantation.

Renal transplantation appears to have a tendency to result in normal left ventricular and left atrial volumes, as well as to lessen left ventricular hypertrophy, without significantly improving left ventricular function.

In chronic renal failure the heart and circulation are affected by several pathological conditions. Increased oxygen demand of the tissues, chronic volume overload, and anaemia, in addition to the presence of an artificial arteriovenous fistula, increase cardiac output, leading to left ventricular dilatation and increased cardiac size. ${ }^{1-6}$ In uraemic patients pronounced left ventricular hypertrophy often occurs principally because of arterial hypertension, ${ }^{6}$ which is frequently severe and difficult to control adequately. Uraemic changes in tissue metabolism and electrolyte balance may also affect cardiac function, leading to uraemic pericarditis ${ }^{178}$ and even possibly to uraemic cardiomyopathy..$^{10}$

Renal transplantation corrects the uraemic metabolic changes and restores the decreased blood haemoglobin concentrations to normal, and often, at least partially, returns the increased blood pressure to normal. Hence restoration of the circulation and cardiac function is expected, and, indeed, cardiac size has been found to decrease, ${ }^{11} 12$ as has left ventricular size and cardiac output. ${ }^{2}$ In a previous study we inves-

Accepted for publication 17 July 1981 tigated the cardiac effects of haemodialysis, ${ }^{6}$ and the purpose of the present study was to investigate, by echocardiography, the cardiac changes caused by renal transplantation, especially its effect on left ventricular size and function. We also wanted to investigate the extent to which the changes occurring after renal transplantation could be predicted by the acute cardiac changes seen after haemodialysis.

\section{Patients and methods}

Nine male and four female patients with chronic renal failure and uraemia, comprising the consecutive cases of successful renal transplantation, were investigated before and after haemodialysis, an average of four and a half months before renal transplantation and again at a mean of a little over nine months after transplantation. The transplant was considered to function well when the serum creatinine level remained below 150 $\mu \mathrm{mol} / \mathrm{l}$ without haemodialysis. The ages of the patients ranged from 20 to 50 years, with a mean age of 31 years. Ten of the patients were hypertensive and three were normotensive. Antihypertensive treatment usually consisted of diuretic, beta-blocking, and vaso- 
dilating drugs. The cause of chronic renal failure was glomerulonephritis in 10 patients, interstitial -nephritis in one, hydronephrosis in one, and renal amyloid disease in one. All the patients had an arteriovenous fistula in either upper extremity, constructed by the same surgeon, in studies performed both before and after renal transplantation. All the patients were treated by corticosteroids and immunosuppressive drugs after transplantation. None of the patients had a history of myocardial infarction or evidence of coronary artery disease. Before transplantation all the patients were treated by haemodialysis lasting four hours three times a week.

The echocardiographic examinations were made immediately before and within 30 minutes of haemodialysis. Echocardiograms were obtained with an ATL Mark III real-time echocardiographic system using a mechanical sector transducer with a $90^{\circ}$ angle and a frequency of 3.0 megaHertz. The M-mode echocardiogram, electrocardiogram, and carotid pulse tracing were recorded with a Honeywell fibreoptic recorder equipped with a black and white adapter using 3M-dry silver paper and $50 \mathrm{~mm} / \mathrm{s}$ paper speed. In the initial studies, a Picker Echoview ultrasonoscope equipped with a Polaroid film recorder was used. Echocardiograms were recorded by the same echocardiographer (MI) using an accurate standard technique ${ }^{13}$ routinely employed in this laboratory. ${ }^{14}$ The left ventricular end-diastolic diameter (LVDd) and wall thicknesses were measured at the point of the $R$ wave in the electrocardiogram. The left ventricular volumes were calculated using the prolate ellipse formula, and the cardiac output was calculated as the product of the left ventricular stroke volume and the heart rate. The fractional shortening of the left ventricular minor axis in systole (FS) was calculated as (LVDd-LVDs)/LVDd $\times 100$, where LVDs is left ventricular end-systolic diameter. The mean velocity of the left ventricular circumferential muscle fibre shortening (mVCF) was calculated as previously described, ${ }^{15}$ using in the calculation the left ventricular ejection time measured from the simultaneously

recorded carotid pulse tracing. The left ventricular mass was determined using LVDd and the mean value of the left ventricular posterior wall and interventricular septal thicknesses according to the formula previously established. ${ }^{16}$

Student's paired $t$ test was used in analysing the differences between the results of serial studies. Two-variable linear regression estimates were used in the correlation studies.

\section{Results}

In no patients were the left ventricular contractions found to be asymmetric in real-time two dimensional studies. In three patients before, and in one patient after renal transplantation, a slight pericardial effusion was found, which did not seem to disturb cardiac function much ${ }^{17}$ Nine of the 10 patients with arterial hypertension before transplantation also needed antihypertensive drugs after operation, though in reduced amounts.

The renal transplantation did not cause significant changes in body weight, diastolic blood pressure, heart rate, left ventricular ejection time, fractional shortening, or mean velocity of left ventricular circumferential muscle fibre shortening compared with the measurements made either before or after haemodialysis treatment (Tables 1 and 2).

\section{CHANGES VS MEASUREMENTS MADE BEFORE} HAEMODIALYSIS (Tables 1 and 2)

As a result of the renal transplantation, the systolic blood pressure decreased by $19.6 \pm 28.2 \mathrm{mmHg}$ (p $<$ 0.05 ), the serum potassium concentration decreased by $1.7 \pm 1.1 \mathrm{mmol} / \mathrm{l}(\mathrm{p}<0.001)$, the serum urea concentration decreased by $21.1 \pm 7.1 \mathrm{mmol} / \mathrm{l}(\mathrm{p}<$ 0.001 ), and the blood haemoglobin concentration increased by $61.5 \pm 33.6 \mathrm{~g} / 1$ (p $<0.001)$. In our laboratory the normal range of serum potassium concentrations is 3.5 to $5.3 \mathrm{mmol} / \mathrm{l}$ and that of serum urea is 2.5 to $6.0 \mathrm{mmol} / \mathrm{l}$.

The echocardiographic measurements showed the

Table 1 Physical and laboratory data

\begin{tabular}{|c|c|c|c|c|c|}
\hline & \multirow{2}{*}{$\begin{array}{l}\text { Before } \\
\text { haemodialysis }\end{array}$} & \multirow{2}{*}{$\begin{array}{l}\text { After } \\
\text { haemodialysis }\end{array}$} & \multirow{2}{*}{$\begin{array}{l}\text { After } \\
\text { transplantation }\end{array}$} & \multicolumn{2}{|l|}{$P$ value } \\
\hline & & & & $B H$ vs $A T$ & $A H$ vs $A T$ \\
\hline \multirow{4}{*}{$\begin{array}{l}\text { Body weight }(\mathrm{kg}) \\
\text { Blood pressure }(\mathrm{mmHg}) \\
\text { Systolic } \\
\text { Diastolic } \\
\text { Heart rate }(\mathrm{bt} / \mathrm{min}) \\
\text { LVET (ms) } \\
\text { Blood haemoglobin }(\mathrm{g} / \mathrm{l}) \\
\text { Serum potassium }(\mathrm{mmol} / \mathrm{l}) \\
\text { Serum urea }(\mathrm{mmol} / \mathrm{l})\end{array}$} & $62 \cdot 7 \pm 8 \cdot 1$ & $61 \cdot 2 \pm 8.6$ & $63 \cdot 2 \pm 8 \cdot 9$ & NS & NS \\
\hline & $\begin{aligned} 170.0 & \pm 33.6 \\
95.4 & \pm 16.6 \\
76.8 & \pm 14.4 \\
279 & \pm 24\end{aligned}$ & $\begin{aligned} 156 \cdot 2 & \pm 31 \cdot 0 \\
86.2 & \pm 13 \cdot 3 \\
77.7 & \pm 14.5 \\
266 & \pm 26\end{aligned}$ & $\begin{array}{c}150.2 \pm 25.9 \\
94.2 \pm 11 \cdot 9 \\
71 \cdot 3 \pm 9 \cdot 1 \\
270 \pm 21\end{array}$ & $\begin{array}{l}0.05 \\
\text { NS } \\
\text { NS } \\
\text { NS }\end{array}$ & $\begin{array}{l}\text { NS } \\
\text { NS } \\
\text { NS } \\
\text { NS }\end{array}$ \\
\hline & $61.5 \pm 14.1$ & $3.81+0.29$ & $\begin{array}{c}122.9 \pm 27.1 \\
3.84 \pm 0.62\end{array}$ & $\begin{array}{l}0.001 \\
0.001\end{array}$ & NS \\
\hline & $\begin{aligned} 5.54 \pm & 0.96 \\
28.8 & \pm 7.4\end{aligned}$ & $\begin{aligned} 3.81 \pm 0.29 \\
12.5 \pm 4.3\end{aligned}$ & $\begin{array}{l}3.84 \pm 0.62 \\
7.6 \pm 2.7\end{array}$ & 0.001 & 0.001 \\
\hline \multicolumn{6}{|c|}{$\begin{array}{l}\text { Mean } \pm \text { standard deviation. } \mathrm{BH} \text {, before haemodialysis; } \\
\text { ejection time; } \mathrm{n}=13 \text {. }\end{array}$} \\
\hline
\end{tabular}


Table 2 Echocardiographic data

\begin{tabular}{|c|c|c|c|c|c|}
\hline \multirow[b]{3}{*}{$\begin{array}{l}\text { Left atrial diameter }(\mathrm{mm}) \\
\text { Cardiac index }\left(1 / \mathrm{min} \text { per } \mathrm{m}^{2}\right) \\
\text { Left ventricle }\end{array}$} & \multirow{3}{*}{ 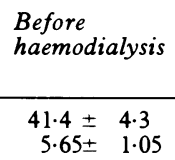 } & \multirow{3}{*}{$\begin{array}{l}\begin{array}{l}\text { After } \\
\text { haemodialysis }\end{array} \\
38.5 \pm 5 \cdot 9 \\
5 \cdot 41 \pm 1 \cdot 31\end{array}$} & \multirow{3}{*}{$\begin{array}{l}\begin{array}{l}\text { After } \\
\text { transplantation }\end{array} \\
35 \cdot 8 \pm 4.5 \\
3.94 \pm 1.48\end{array}$} & \multicolumn{2}{|l|}{$P$ value } \\
\hline & & & & \multirow{2}{*}{$\begin{array}{l}B H \text { vs } A T \\
0.005 \\
0.005\end{array}$} & \multirow{2}{*}{$\begin{array}{l}A H \text { vs } A T \\
\text { NS } \\
0.01\end{array}$} \\
\hline & & & & & \\
\hline $\begin{array}{l}\text { End-diastolic diameter }(\mathrm{mm}) \\
\text { End-systolic diameter }(\mathrm{mm}) \\
\text { Fractional shortening }(\%) \\
\text { mVCF }(\text { circ/s) } \\
\text { Posterior wall thickness }(\mathrm{mm}) \\
\text { Mass index }\left(\mathrm{g} / \mathrm{m}^{2}\right)\end{array}$ & $\begin{array}{c}56 \cdot 6 \pm 4 \cdot 4 \\
39 \cdot 3 \pm 4 \cdot 8 \\
30 \cdot 6 \pm 5 \cdot 3 \\
1 \cdot 09 \pm 0 \cdot 20 \\
13 \cdot 2 \pm 2 \cdot 1 \\
197 \cdot 7 \pm 44 \cdot 8\end{array}$ & $\begin{array}{c}54 \cdot 2 \pm 3 \cdot 4 \\
36 \cdot 4 \pm 3 \cdot 3 \\
32 \cdot 9 \pm 4 \cdot 3 \\
1 \cdot 24 \pm 0 \cdot 19 \\
13 \cdot 2 \pm 1 \cdot 9 \\
178 \cdot 2 \pm 36 \cdot 8\end{array}$ & $\begin{array}{c}49 \cdot 6 \pm 5 \cdot 9 \\
32 \cdot 8 \pm 6 \cdot 1 \\
34 \cdot 3 \pm 7 \cdot 1 \\
1 \cdot 25 \pm 0 \cdot 24 \\
12 \cdot 2 \pm 2 \cdot 3 \\
143 \cdot 5 \pm 47 \cdot 3\end{array}$ & $\begin{array}{l}0.001 \\
0.005 \\
\text { NS } \\
\text { NS } \\
0.05 \\
0.001\end{array}$ & $\begin{array}{l}0.01 \\
0.05 \\
\text { NS } \\
\text { NS } \\
0.05 \\
0.01\end{array}$ \\
\hline
\end{tabular}

Mean \pm standard deviation. BH, before haemodialysis; AH, after haemodialysis; AT, after renal transplantation; mVCF, mean velocity of the circumferential muscle fibre shortening; $\mathbf{n}=13$.

left atrial diameter to have decreased by $5.5 \pm 5.4 \mathrm{~mm}$ $(p<0.01)$ (Fig. 1), left ventricular end-diastolic diameter to have decreased by $7.0 \pm 5.1 \mathrm{~mm}(\mathrm{p}<$ $0.001)$, left ventricular end-systolic diameter to have decreased by $6.5 \pm 6.7 \mathrm{~mm}(\mathrm{p}<0.005)$ (Fig. 2 ), and the cardiac index to have decreased by $1.7 \pm$ $1.71 / \mathrm{min}$ per $\mathrm{m}^{2}(\mathrm{p}<0.005)$ (Fig. 3). Renal transplantation also caused a significant reduction in left ventricular hypertrophy: the left ventricular posterior wall thickness decreased by $1.1 \pm 1.7 \mathrm{~mm}(\mathrm{p}<0.05)$ and the left ventricular mass diminished by $54.2 \pm$ $43.3 \mathrm{~g} / \mathrm{m}^{2}(\mathrm{p}<0.001)$.

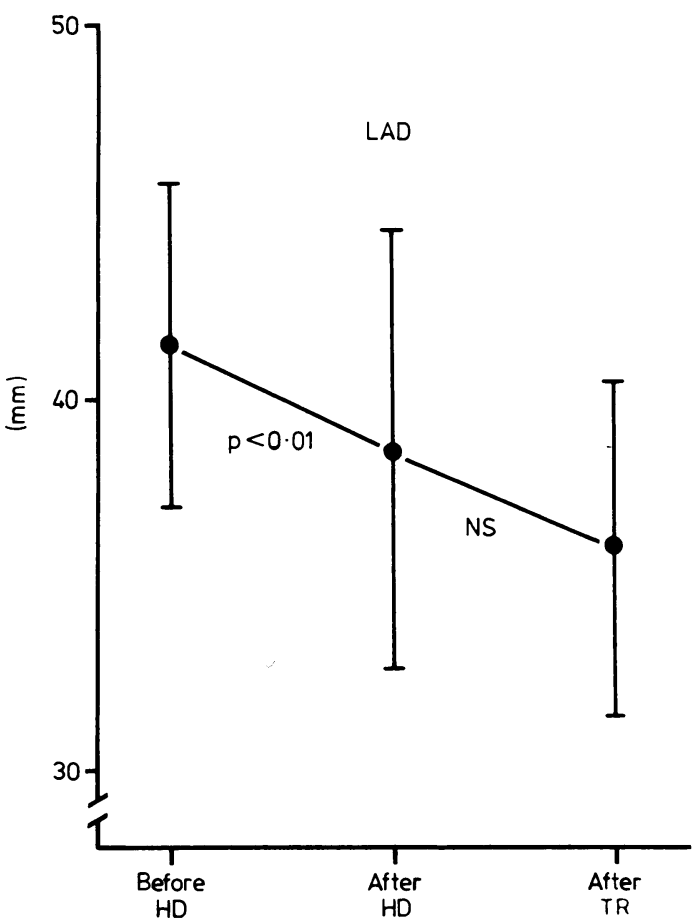

Fig. 1 The effect of haemodialysis (HD) and renal transplantation (TR) on left atrial diameter (LAD).
The patients' ages correlated negatively with fractional shortening $(\mathrm{r}=-0.679, \mathrm{p}<0.05)$ and mean velocity of left ventricular circumferential muscle fibre shortening $(r=-0.632, p<0.05)$ measured before haemodialysis.

CHANGES VS MEASUREMENTS MADE AFTER HAEMODIALYSIS (Tables 1 and 2)

After renal transplantation, the serum urea concentration decreased by $4.8 \pm 3.3 \mathrm{mmol} / \mathrm{l}(\mathrm{p}<0.001)$ and, by echocardiographic measurement, left ventricular

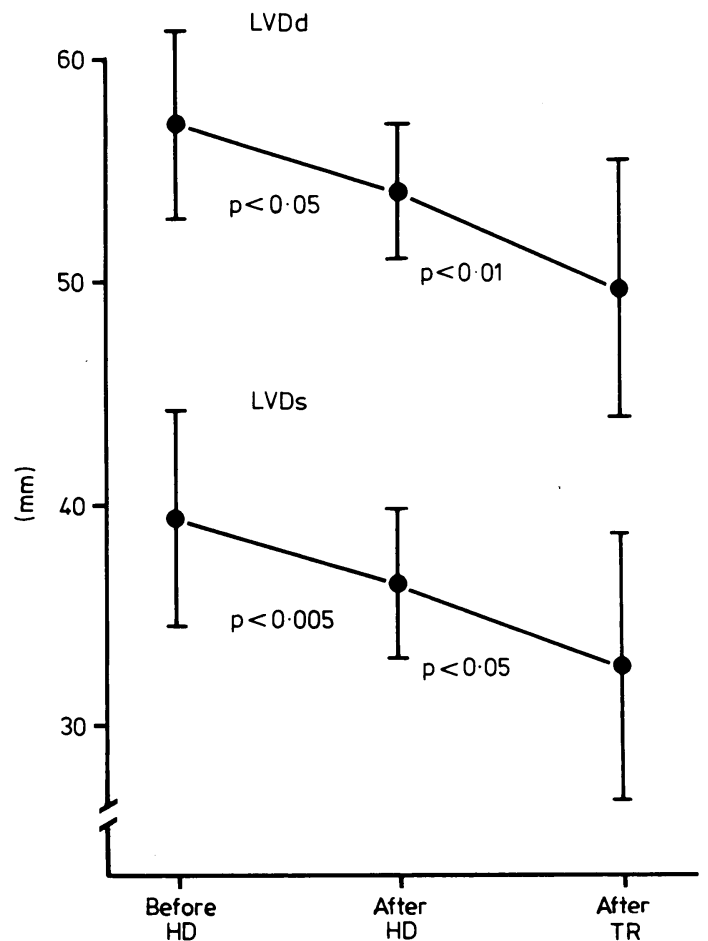

Fig. 2 The effect of haemodialysis (HD) and renal transplantation (TR) on left ventricular end-diastolic (LVDd) and end-systolic (LVDs) diameters. 


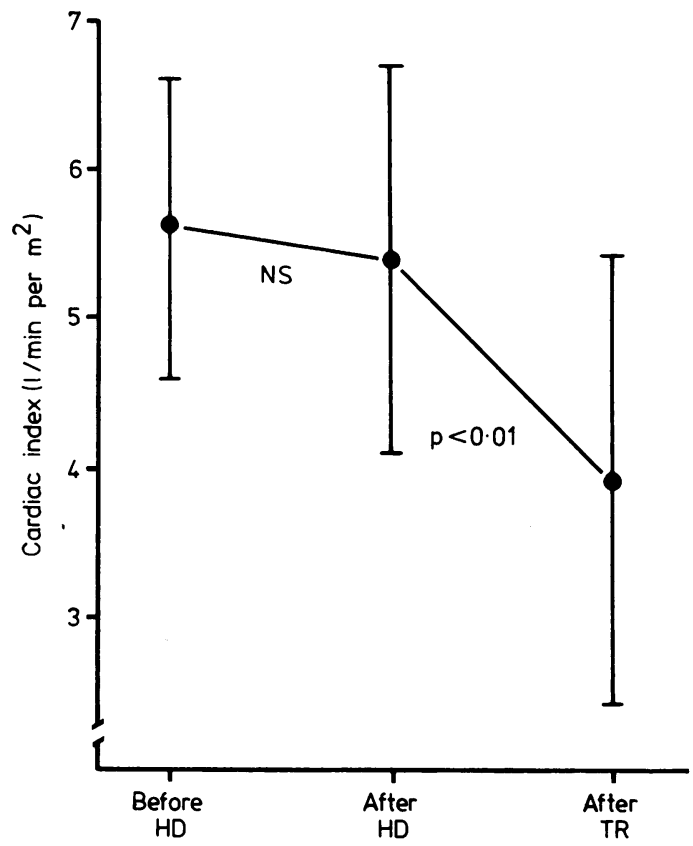

Fig. 3 The effect of haemodialysis $(H D)$ and renal transplantation (TR) on cardiac index.

end-diastolic diameter decreased by $4.6 \pm 4.4 \mathrm{~mm}$ (p $<0.01$ ) (Fig. 2), left ventricular end-systolic diameter decreased by $3.5 \pm 5.2 \mathrm{~mm}(\mathrm{p}<0.05)$ (Fig. 2), and the cardiac index decreased by $1.5 \pm 1.7 \mathrm{l} / \mathrm{min}$ per $\mathrm{m}^{2}(\mathrm{p}$ $<0.01$ ) (Fig. 3).

\section{CORRELATIONS BETWEEN CHANGES SEEN AFTER} RENAL TRANSPLANTATION

The changes in the measurements made before haemodialysis and after renal transplantation were evaluated. The changes in the measurements as a result of renal transplantation did not correlate with the time between the operation and the postoperative measurement. There was a significant positive correlation between the changes in systolic blood pressure and left ventricular end-systolic diameter $(r=0.590$, $p<0.05)$. The systolic blood pressure measured before haemodialysis correlated positively with its decrease because of the renal transplantation $(r=$ $0.662, \mathrm{p}<0.05$ ) and the diastolic blood pressure with its change $(r=0.746, p<0.01)$. The changes in systolic blood pressure correlated negatively with the changes in fractional shortening $(\mathrm{r}=-0.607, \mathrm{p}<$ 0.05 ) and in mean velocity of left ventricular circumferential muscle fibre shortening $(r=-0.746, p$ $<0.01)$. The changes in the left atrial diameter correlated positively with the changes in left ventricular end-diastolic diameter $(r=0.722, p<0.01)$ and with the changes in the left ventricular mass $(r=0.588, p$ $<0.05)$. The changes in the cardiac index correlated $\rightleftharpoons$ positively with the changes in the left ventricular mass $(r=0.736, p<0.01)$.

PREDICTIVE VALUE OF CHANGES RESULTING FROM HAEMODIALYSIS

The changes in body weight caused by haemodialysis correlated positively with the changes caused by the $\vec{O}$ renal transplantation as regards the systolic blood pressure $(r=0.674, p<0.05)$ and diastolic blood pressure $(r=0.572, p<0.05)$. This correlation was negative as regards the changes in fractional shortening $(r=-0.617, p<0.05)$. The changes in the diastolic blood pressure as a result of haemodialysis corre- iv lated with the changes in the left atrial diameter $\vec{v}$ caused by the renal transplantation $(r=0.622, p<\circlearrowleft$ 0.05 ). The haemodialysis changes of left ventricular $\frac{\rho}{工}$ end-systolic diameter correlated negatively with the transplantation changes in mean velocity of left ventricular circumferential muscle fibre shortening $(r=$ $-0.604, p<0.05$ ) and the haemodialysis changes of fractional shortening correlated positively with the transplantation changes of fractional shortening $(r=\vec{\varnothing}$ $0.582, p<0.05)$ and mean velocity of left ventricular ? circumferential muscle fibre shortening $(r=0.738, p$ 응 $<0.01$ ). The haemodialysis changes in the latter predicted its changes after transplantation $(r=0.733, p$ $<0.01$ ), and the haemodialysis changes of the cardiac index predicted the changes in left ventricular posterior wall thickness $(r=0.593, p<0.05)$ caused by renal transplantation, but not the changes in left ventricular mass.

\section{Discussion}

Normal blood haemoglobin and serum potassium concentrations as well as nearly normal serum urea concentration after renal transplantation showed that the procedure corrected the abnormal metabolic and electrolyte balance. This was associated with the disappearance of hypervolaemia and hence a decrease in the left ventricular filling pressure. The serum potas- $\frac{D}{0}$ sium concentrations were at the low end of the normal range, perhaps because of diuretic and corticosteroid $N$ treatment. Unlike haemodialysis, 2618 renal transplantation did not cause a significant reduction in body weight because, in spite of the decrease of water retention and thus extracellular volume, the muscle and fat tissue apparently increased as a result of nor- $\stackrel{\circ}{工}$ mal metabolism and also corticosteroid treatment. $\stackrel{\Phi}{\infty}$ Though the diastolic blood pressure did not change ${ }^{+}$ significantly, the systolic blood pressure decreased $\frac{0}{0}$ after renal transplantation, indicating a decreased left $\underset{\mathbb{D}}{\stackrel{D}{ }}$ ventricular afterload. Though the arteriovenous $\frac{?}{\oplus}$ fistula was left open after transplantation as a reserve 
for possible future complications, both the left ventricular preload and afterload seemed to decrease as a result of operation, and hence changes in the echocardiographic measurements were expected.

The mean left ventricular diameter decreased both in systole and diastole, reaching normal values, so that the cardiac index also decreased significantly because of the decreased left ventricular preload. The mean cardiac index, however, still remained high because of the open arteriovenous fistula. The correction of anaemia also resulted in decreased cardiac output because of increased viscosity and improved oxygen carrying capacity of the blood. In spite of the decreased preload and thus decreased Starling's effect, and in spite of the increased blood viscosity, the indices of left ventricular function showed a tendency to increase, though not significantly, which means that the decreasing effect of the reduced left ventricular preload on left ventricular function was compensated for by the decreased afterload and increased ventricular contractility, perhaps because of the mechanical advantage of a smaller heart rather than because of favourable changes in metabolism and electrolyte balance. The changes in left ventricular volumes and function found in the present study are in agreement with the findings of Riley et al. ${ }^{2}$ in four patients. Decreases in the cardiac volume ${ }^{11}$ and cardiothoracic ratio ${ }^{12}$ measured from chest $x$-rays have also been found after renal transplantation.

The left ventricular wall thickness and mass decreased significantly after renal transplantation because of decreased cardiac output and decreased ventricular afterload. Hypertension is obviously the most important factor in causing left ventricular hypertrophy in chronic renal failure. ${ }^{6}$ Though the cause of increased blood pressure is undoubtedly renal in patients with chronic renal failure, hypertension seems to be frequently, at least partially, irreversible. Possible causes for this are postoperative steroid therapy, the influence of the patient's own kidneys, and chronic rejection. ${ }^{19}$ Only in one of our patients was hypertension entirely cured after transplantation and this was one of the two patients whose own kidneys were removed. Because of residual hypertension and also because of the open arteriovenous fistula, the left ventricular wall thickness and mass still remained greater than normal. The extreme left ventricular hypertrophy may also be partially irreversible even though its cause is removed. Because the effect of the renal transplantation seemed to be greater on the left ventricular preload than on the afterload, it is not surprising that the changes in blood pressure did not correlate significantly with the changes in left ventricular wall thickness or mass. On the other hand, the changes in systolic blood pressure correlated well with the changes of left ventricular end-systolic diameter, fractional shortening, and mean velocity of left ventricular circumferential muscle fibre shortening, reflecting the significance of afterload on left ventricular function, on which also the modern vasodilator treatment of cardiac failure is based.

The left atrial diameter also decreased significantly after renal transplantation and its changes correlated significantly with the changes in left ventricular diastolic volume and mass. In previous studies we found that the left atrial size depended on the degree of left ventricular hypertrophy and therefore also on the decreased left ventricular diastolic compliance. ${ }^{620} \mathrm{As}$ the changes in left ventricular mass are dependent on the changes in preload and afterload, both of which have an effect on cardiac output, the correlation between the changes in left ventricular mass and cardiac index was to be expected.

PREDICTIVE VALUE OF CHANGES CAUSED BY HAEMODIALYSIS

As haemodialysis causes a very acute decrease in left ventricular preload, 2618 it was of interest to discover which variables, if any, could predict the cardiac changes caused by renal transplantation. The effect of haemodialysis on left ventricular afterload appears to be less than on preload, because in our previous work haemodialysis caused a significant decrease only in diastolic blood pressure. ${ }^{6}$ The correlations seen between the changes in body weight or diastolic blood pressure resulting from haemodialysis and the changes caused by renal transplantation were slight and have no obvious explanation. The decrease in water loss and hence body weight after haemodialysis is adjustable and so perhaps greater in patients with more advanced renal disease and hypertension; in these patients, renal transplantation perhaps also causes a more distinct decrease in blood pressure and a subsequent increase in left ventricular function.

On the other hand, however, the changes in left ventricular end-systolic diameter and the indices of left ventricular function caused by haemodialysis more closely predicted the changes of left ventricular performance caused by renal transplantation. Hence measurement of the changes in left ventricular endsystolic diameter, fractional shortening, and mean velocity of left ventricular circumferential muscle fibre shortening caused by haemodialysis could be applicable in practice to predict the changes in left ventricular function after renal transplantation.

Renal transplantation thus apparently decreases left ventricular and left atrial volumes towards normal, and also lessens left ventricular hypertrophy, but it does not significantly improve left ventricular function. The changes in left ventricular end-systolic size and the indices of left ventricular function resulting from haemodialysis are apparently indicative of 
changes in left ventricular function caused by renal transplantation.

\section{References}

1 Scharf S, Wexler J, Longnecker RE, Blaufox MD. Cardiovascular disease in patients on chronic hemodialytic therapy. Prog Cardiovasc Dis 1980; 22: 343-56.

2 Riley SM Jr, Blackstone EH, Sterling WA, Diethelm AG. Echocardiographic assessment of cardiac performance in patients with arteriovenous fistulas. Surg Gynecol Obstet 1978; 146: 203-8.

3 Saha SP, Roman J, Zaidi SA. Hemodynamic effects of arteriovenous fistula and bovine graft fistula used for hemodialysis. Am Surg 1978; 44: 742-3.

4 Bergrem H, Flatmark A, Simonsen S. Dialysis fistulas and cardiac failure. Acta Med Scand 1978; 204: 191-3.

5 von Bibra H, Castro L, Autenrieth G, McLeod A, Gurland $\mathrm{HJ}$. The effects of arteriovenous shunts on cardiac function in renal dialysis patients-an echocardiographic evaluation. Clin Nephrol 1978; 9: 205-9.

6 Ikäheimo M, Huttunen K, Takkunen J. Cardiac effects of chronic renal failure and haemodialysis treatment: hypertensive versus normotensive patients. $\mathrm{Br}$ Heart $\mathcal{f}$ 1981; 45: 710-6.

7 Mitchell AG. Pericarditis during chronic haemodialysis therapy. Postgrad Med f 1974; 50: 741-5.

8 Silverberg S, Oreopoulos DG, Wise DJ, et al. Pericarditis in patients undergoing long-term hemodialysis and peritoneal dialysis. Incidence, complications and management. Am F Med 1977; 63: 874-80.

9 Penpargkul S, Kuziak J, Scheuer J. Effect of uremia upon carbohydrate metabolism in isolated perfused rat heart. F Mol Cell Cardiol 1975; 7: 499-511.

10 Drüeke T, Le Pailleur C, Meilhac B, et al. Congestive cardiomyopathy in uraemic patients on long term haemodialysis. $\mathrm{Br} \mathrm{Med} \mathcal{F} 1977$; i: 350-3.
11 Helin B. Heart volume in human kidney transplantation. Acta Radiol 1972; suppl 314.

12 Ianhez LE, Lowen J, Sabbaga E. Uremic myocardiopathy. Nephron 1975; 15: 17-28.

13 Feigenbaum H. Echocardiography. Philadelphia: Lea \& Febiger, 1972: 37-39.

14 Ikäheimo M, Takkunen J. Echocardiography in assessment of mitral valve disease II. Left atrium and left ventricle. Ann Clin Res 1977; 9: 321-29.

15 Cooper RH, O'Rourke RA, Karliner JS, Peterson KL, Leopold GR. Comparison of ultrasound and cineangiographic measurements of the mean rate of circumferential fiber shortening in man. Circulation 1972; 46: 914-23.

16 Troy BL, Pombo J, Rackley CE. Measurement of left ventricular wall thickness and mass by echocardiography. Circulation 1972; 45: 602-11.

17 Firestein G, Hensley C, Varghese PJ. Left ventricular function in presence of small pericardial effusion. Echocardiographic study. Br Heart $\mathcal{F}$ 1980; 43: 382-7.

18 Hung J, Harris PJ, Uren RF, Tiller DJ, Kelly DT. Uremic cardiomyopathy-effect of hemodialysis on left ventricular function in end-stage renal failure. $N$ Engl $\mathcal{F}$ Med 1980; 302: 547-51.

19 Hulme B. Medical aspects of renal transplantation. In: Jones NF, ed. Recent advances in renal disease. Edinburgh, London, \& New York: Churchill Livingstone, 1975: 234

20 Ikäheimo MJ, Palatsi IJ, Takkunen JT. Noninvasive evaluation of the athletic heart: sprinters versus endurance runners. Am $\mathcal{F}$ Cardiol 1979; 44: 24-30.

Requests for reprints to Dr Markku Ikäheimo, Cardiovascular Division, Department of Medicine, Oulu University Central Hospital, SF-90220 Oulu 22, Finland. 